\title{
The CDD System in Computed Tomographic Diagnosis of Diverticular Disease
}

\section{Das CDD System in der computertomografischen Diagnostik der Divertikelkrankheit}

Authors

Daniel Pustelnik', Fabian Henry Jürgen Elsholtz ${ }^{1}$, Christian Bojarski², Bernd Hamm¹, Stefan Markus Niehues ${ }^{1}$

Affiliation

1 Institute of Radiology, Charité - Universitätsmedizin Berlin, Germany

2 Medical Department, Division of Gastroenterology, Infectiology and Rheumatology, Charité

Universitätsmedizin Berlin Campus Benjamin Franklin, Berlin, Germany

Key words

diverticulitis, diverticulosis, $\mathrm{CDD}, \mathrm{CT}$, diverticular disease

received 21.09.2016

accepted 22.03.2017

Bibliography

DOI https://doi.org/10.1055/s-0043-110770

Published online: 26.6.2017 | Fortschr Röntgenstr 2017; 189: 740-747 @ Georg Thieme Verlag KG, Stuttgart · New York

ISSN 1438-9029

Correspondence

Priv.-Doz. Dr. Stefan Markus Niehues, MHBA

Institute of Radiology, Charité - Universitätsmedizin Berlin, Hindenburgdamm 30, 12203 Berlin, Germany

Tel.: ++49/30/450627718

Fax: $++49 / 30 / 45026746$

Stefan.Niehues@charite.de

\section{ABSTRACT}

Purpose This overview sums up the Classification of Diverticular Disease (CDD) with regard to its application in computed tomographic diagnosis and briefly recapitulates its targeted advantages over preliminary systems. Primarily, application of the CDD in computed tomography diagnostics is described. Differences with respect to the categories of the older systems are pointed out on the level of each CDD type using imaging examples.

Materials and Methods The presented images are derived from our institute according to the S2k criteria. Literature was researched on PubMed.

Results The CDD constitutes an improvement compared to older systems for categorizing the stages of diverticular disease. It provides more discriminatory power on the descriptive-morphological level and defines as well as differ- entiates more courses of the disease. Furthermore, the categories translate more directly into state-of-the-art decisionmaking concerning hospitalization and therapy.

Conclusion The CDD should be applied routinely in the computed tomographic diagnosis of diverticular disease. Typical imaging patterns are presented.

\section{Key points}

- The CDD is superior to its predecessors. It better stratifies categories of diverticular disease by morphology, course and modern options for treatment of the disease.

- Computed tomography is the dominant imaging modality. Different stages show typical imaging patterns.

- Non-abscessed phlegmonous peridiverticulitis is now interpreted as an uncomplicated course.

- Minimal paracolic air does not constitute a full-fledged perforation in terms of a pneumoperitoneum (CDD type 2c).

\section{Citation Format}

- Pustelnik D, Elsholtz FH, Bojarski C et al. The CDD System in Computed Tomographic Diagnosis of Diverticular Disease. Fortschr Röntgenstr 2017; 189: 740-747

\section{ZUSAMMENFASSUNG}

Ziel Die vorliegende Übersichtsarbeit fasst die Classification of Diverticular Disease (CDD) mit Blick auf ihre Anwendung in der computertomografischen Diagnostik zusammen und rekapituliert ihre angestrebten Vorteile gegenüber älteren Systemen. Primär soll die Anwendung der CDD in der computertomografischen Befundung veranschaulicht werden. Unterschiede zu den Kategorien der Vorläufersysteme werden auf Ebene der einzelnen CDD-Typen an Bildbeispielen aufgezeigt.

Material und Methode Die gezeigten Bilder stammen aus der eigenen Klinik und wurden entsprechend der S2k-Leitlinie definiert. Ferner wurde eine PubMed-Literaturrecherche durchgeführt.

Ergebnisse Die CDD stellt einen Fortschritt gegenüber älteren Klassifikationssystemen der Divertikelkrankheit dar. Sie bietet deskriptiv-morphologisch mehr Trennschärfe und erfasst und differenziert mehr Verläufe. Darüber hinaus übersetzen sich ihre Kategorien direkter in zeitgemäße Indikationsstellung von Hospitalisierung und Therapie. 
Schlussfolgerung Die CDD sollte in der alltäglichen computertomografischen Befundung der Divertikelkrankheit verwendet werden. Hierzu wurden entsprechende Bildbeispiele hinterlegt.

\section{Introduction}

Diverticulosis is a widespread disease seen in increasingly younger patients in Western countries in particular [1]. To date, the stages have typically been stratified according to Hinchey et al. as modified by Wasvary et al. [2, 3] (Hinchey-Wasvary classification) in Anglo-America and according to Hansen \& Stock in Germany [4]. None of these classification systems fully reflects the current state of knowledge of the courses of diverticular disease and its prognosis, diagnosis, and treatment options.

The Classification of Diverticular Disease (CDD) has been available since the publication of the S2k Guidelines on Diverticular Disease/Diverticulitis [5] in 2014. The classification system based on these modern guideline recommendations is intended to combine the descriptive-morphological qualities of the earlier systems and to better reflect currently available interdisciplinary treatment options. Schreyer at al. reviewed these guidelines with respect to their significance for radiology and their effect on diagnostic and therapeutic algorithms for diverticular disease [6].

Computed tomography (CT) has largely become established as the method of choice for radiological diagnosis [7]. The present article discusses the different categories with the individual CDD types of this classification with a focus on application in computed tomographic diagnosis. For every stage the article provides typical image material and references to practice-oriented commonalities and differences with respect to previous classification systems.

\section{Basic information}

Colonic diverticula are pseudodiverticula. They are defined in the guidelines as "acquired outpouchings of the mucosa and submucosa through weak spots in the colon wall" [5, 8-10]. Points of passage of vessels are hypothesized to be a structural correlate of these weak spots. Age, genetic variables, and a low-fiber diet are defined as risk factors [10-20]. Additional factors such as medication and comorbidities are the subject of current research [21 - 26]. In this country, the majority of diverticula are seen in the sigmoid colon.

Non-irritated diverticula do not require treatment.

According to the $\mathrm{S} 2 \mathrm{k}$ guidelines, treatment is first required in the case of diverticular disease, defined by the occurrence of symptoms or complications. Typical courses starting with type 2 of the CDD include diverticulitis/peridiverticulitis, abscess formation, a covered or open perforation with peritonitis, bleeding, and stenosis, conglomerate and fistula formation.

\section{Differential diagnoses}

In addition to sigmoid diverticulitis, there are a number of other differential diagnoses that also need to be considered during examination and evaluation. Due to the often non-specific symptoms, medical-surgical, gynecological, and urological diseases must be taken into consideration. This includes all types of colitis (infectious, ischemic, chronic inflammatory, non-inflammatory, medication-induced, radiation-induced, neutropenic), neoplastic processes such as colorectal carcinomas and abdominal and retroperitoneal abscesses and hematomas. In addition, the entire spectrum of differential diagnoses of abdominal pain must be considered, such as appendicitis, irritable bowel syndrome, herniations and adhesions, aneurysms, cystitis, urolithiasis, endometriosis, extrauterine pregnancy, adnexitis, and tubo-ovarian abscess [5, 27].

\section{Classifications}

Various systems for the classification of diverticular disease have been proposed in the past $[12,28]$. From today's standpoint, the most commonly used classification systems, the Hinchey-Wasvary classification and the Hansen \& Stock classification, are suboptimal for different reasons [2, 3]:

The Hinchey classification system commonly used in AngloAmerica was originally created with a limited surgical scope. It was intended to allow stratification of macroscopically perforated courses of diverticulitis according to the correspondingly indicated surgical procedure. Therefore, the differentiation of these courses is good. In the modified version according to Wasvary et al. [3], an attempt was made to expand the Hinchey classification to include courses treated on an outpatient basis (creation of the category "mild clinical diverticulitis"). However, mild diverticulosis, chronic courses, and diverticular bleeding are not included.

In contrast, the Hansen \& Stock classification system used in Germany was designed primarily as a comprehensive taxonomy of the different courses of diverticular disease. It includes categories for mild diverticulosis and for acute, uncomplicated, and complicated diverticulitis and for chronic recurrent courses. However, the Hansen \& Stock classification system does not provide more detailed differentiation between courses with abscess formation, courses with perforations, chronic courses, and courses with bleeding.

The CDD addresses this problem and includes all important courses of the disease on an interdisciplinary basis. At the same time, it differentiates between subtypes that are stratified by 
therapy according to the current state of knowledge. In this regard, it combines and expands the positive qualities of the earlier systems.

\section{CT acquisition technique}

Other than a reference to the minimization of radiation exposure, the guidelines do not provide an explicit recommendation regarding the $\mathrm{CT}$ acquisition technique. The technique can be selected based upon the clinical situation. According to Schreyer et al., high-quality, current comparative studies regarding the diagnostic value of intravenously (i. v.), orally or rectally administered contrast agent are not yet available [6]. The use of intravenous contrast agent is not mandatory to make a diagnosis [29] but intravenously administered contrast agent increases the value of the examination with respect to possible differential diagnoses. The formation of abscesses in acute diverticulitis (CDD type 2: enhancement of the abscess capsule), increased vascularization (starting with CDD type 1a) and phlegmonous reaction of the surrounding tissue (starting with CDD type $1 \mathrm{~b}$ ) are visualized effectively with i. v. contrast agent. Particularly in obese patients, there are initial indications that contrast agent is not necessary needed [27].

The use of orally and rectally administered water-soluble contrast agent is a controversial topic of discussion and is also not defined in the guidelines: There is general consensus that enteral contrast agent administration facilitates the visualization of the intestinal wall and diverticula. Also in the differentiation between intestinal lumen and abscesses or air inclusions and for the visualization of fistulas, stenoses, and perforations with leakage, rectally administered contrast agent can be helpful and provide an indication for surgical treatment. Moreover, luminal masses can be better visualized. Due to a lack of definitive evidence regarding the benefit of enteral contrast enhancement, the design of available studies as well as the implemented examination protocol are highly heterogeneous [5, 6, 29-40].

\section{CDD classification in $\mathrm{CT}$ diagnosis}

- Table 1 presents the types of the CDD with brief explanations and allows comparison of the individual categories of the three discussed classification systems. It also provides an overview of the current treatment options stratified according to CDD type (the article by Schreyer et al. [6] provides a more detailed explanation).

\section{Asymptomatic diverticulosis}

CDD type 0 ( $\triangleright$ Fig. $\mathbf{1}$ ) refers to asymptomatic diverticulosis and corresponds to stage 0 of the Hansen \& Stock classification. It is not included in the Hinchey-Wasvary classification system. After the 40th year of life, it is a common incidental finding without immediate clinical significance in industrialized nations. Non-irritated, thin-walled air figures near the wall are visualized.

\section{Acute uncomplicated diverticular disease/diverticulitis}

CDD types 1a-b refer to acute, uncomplicated courses that can be primarily conservatively treated on an outpatient basis with frequent clinical follow-up.

However, presentation usually only occurs in advanced stages of diverticulitis requiring hospitalization.

CDD type 1a ( $\mathbf{F i g . ~} 2$ ) includes acute symptoms and possibly elevated inflammatory markers in the blood analysis. The detection of CDD type 1a is challenging in CT diagnosis due to the only slight morphological deviation from normal findings and is more successful with knowledge of the patient's symptoms. The guidelines define an intestinal wall thickness of up to $3 \mathrm{~mm}$ as normal. If this value is exceeded near a diverticulum and/or increased vascularization is seen, diverticulitis CDD type $1 \mathrm{a}$ is present from a morphological standpoint. This corresponds to stage 1 of the Hansen \& Stock classification and category 0 of the Hinchey-Wasvary classification.

Diagnosis of phlegmonous peridiverticulitis is more common and easier due to the detection of bleeding into the surrounding tissue ( $\triangleright$ Fig. 3). Its presence defines CDD type 1b on CT. Phlegmonous peridiverticulitis corresponds to stage 1a of the Hinchey-Wasvary classification system. In the Hansen \& Stock classification system, it was defined as a low-grade complicated course (stage 2a) while the CDD now interprets it as a higher-grade uncomplicated course. This categorization as uncomplicated CDD type 1 reflects today's more conservative treatment regimen for peridiverticulitis without abscesses due to the improved antibiotic options ( $\triangleright$ Table 1 ).

\section{Acute complicated diverticulitis}

CDD types 2a-c include the complicated courses of acute diverticulitis.

In addition to meeting the criteria for CDD 1b, CDD types 2a and $2 \mathrm{~b}$ refer to a covered perforation with an abscess with a diameter $\leq 1 \mathrm{~cm}$ (CDD type $2 \mathrm{a}$, > Fig. 4 ) or $>1 \mathrm{~cm}$ (CDD type $2 \mathrm{~b}$, - Fig. 5).

The microabscess of CDD type 2a corresponds most closely to stage $1 \mathrm{~b}$ of the Hinchey-Wasvary classification system. However, abscesses near the focus with a diameter of up to $5 \mathrm{~cm}$ are included in this category in the Hinchey-Wasvary classification system. Abscesses $>5 \mathrm{~cm}$ (category 2 of the Hinchey-Wasvary classification system) correspond to the next higher CDD type (2b). In contrast, stage 2 b of the Hansen \& Stock classification system defines only a single, not further differentiated category for courses with abscess formation. The inpatient treatment concept for courses with covered perforation is currently largely based on the administration of antibiotics and interventional abscess drainage. Surgery is directly indicated in the case of a lack of response to treatment or disease progression, while surgery is first indicated in the inflammation-free interval in the case of response to treatment.

It must be taken into consideration in the diagnosis that covered perforated CDD stages $2 \mathrm{a}$ and $2 \mathrm{~b}$ are often associated with minimal paracolic air and CDD type $2 c$ is only indicated in the case of the detection of free abdominal air and/or fluid with peritonitis. CDD type 2c differentiates between purulent peritoni- 


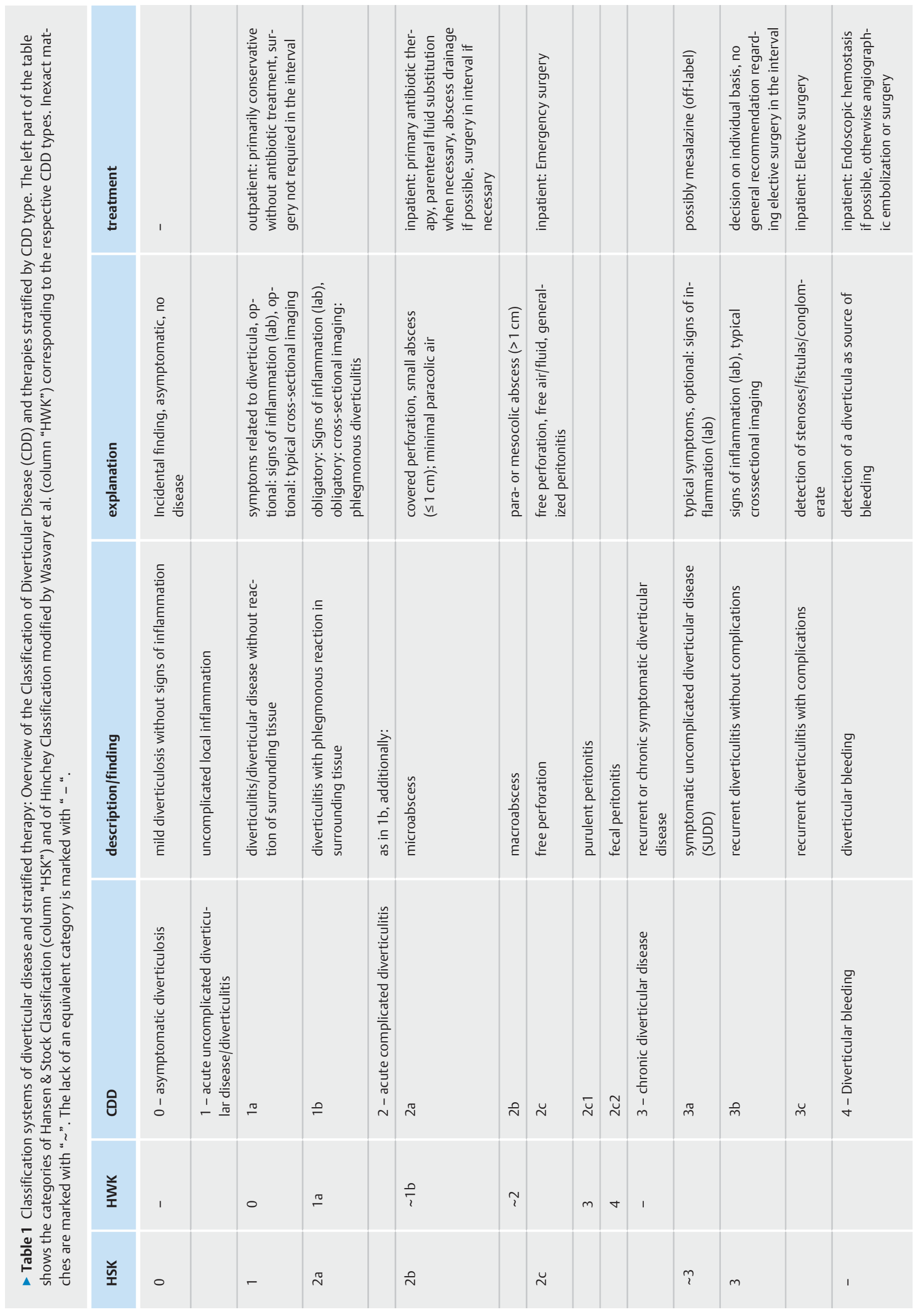



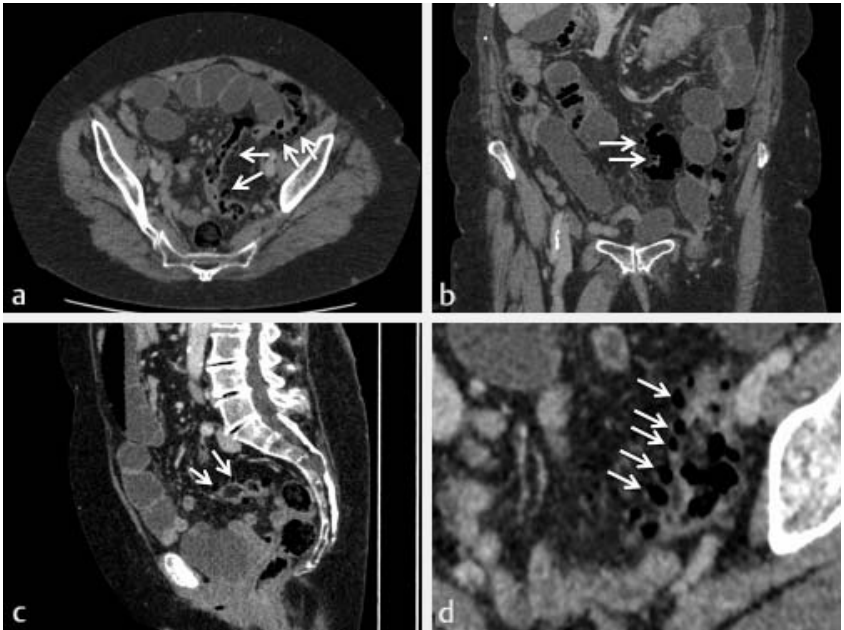

- Fig. 1 CDD type 0: Abdominal post-contrast CT scan of a 76-yearold woman. Axial a, coronal b, sagittal $\mathbf{c}$ and enlarged axial plane $\mathbf{d}$. This diverticular disease was an incidental finding. The non-irritated diverticula can be perceived as round figures of air on the side of the bowel measuring 5-10 mm (see arrows). No increased vascularization or stranding of the adjacent fat can be seen.
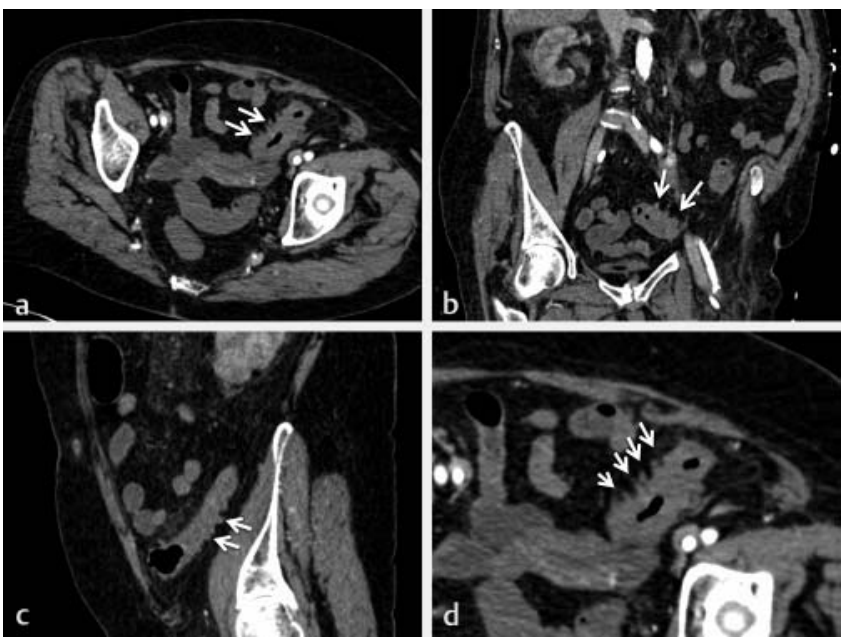

- Fig. 2 CDD type 1a: Abdominal CT scan of a 73-year-old woman with intravenous contrast agent. Axial a, coronal b, sagittal $\mathbf{c}$ and enlarged axial plane $\mathbf{d}$. The inflamed diverticula show a tailed, thickened wall (see arrows) and lightly increased vascularization. No stranding of the adjacent fat can be seen.

tis (CDD 2c1, - Fig. 6) and fecal peritonitis (CDD 2c2) and requires emergency surgical intervention. Stage $2 c$ of the Hansen \& Stock classification system includes free perforations without further differentiation, while categories 3 (purulent peritonitis) and 4 (fecal peritonitis) of the Hinchey-Wasvary classification correspond to CDD types 2c1 and 2c2.

\section{Chronic diverticular disease}

CDD types 3a-c differentiate between chronic types of diverticular disease. The Hinchey-Wasvary classification system does not include chronic courses. Stage 3 of the Hansen \& Stock classifica-
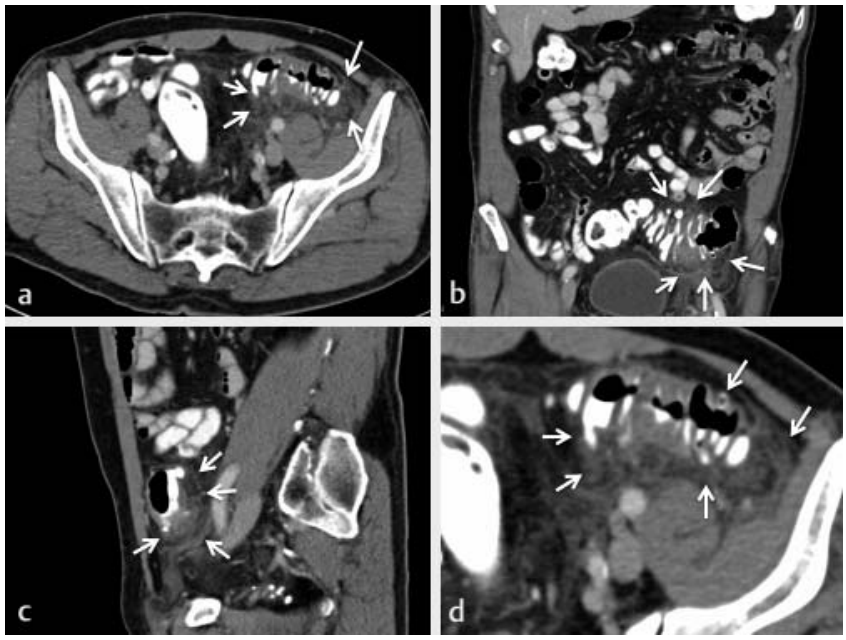

- Fig. 3 CDD type 1b: Abdominal CT scan of a 71-year-old man with intravenous, oral, and rectal positive contrast agents. Axial a, coronal $\mathbf{b}$, sagittal $\mathbf{c}$ and enlarged axial plane $\mathbf{d}$. In addition to the thickened bowel wall and the increased vascularization, CDD type $1 \mathrm{~b}$ is defined by a phlegmonous reaction of the surrounding tissue.
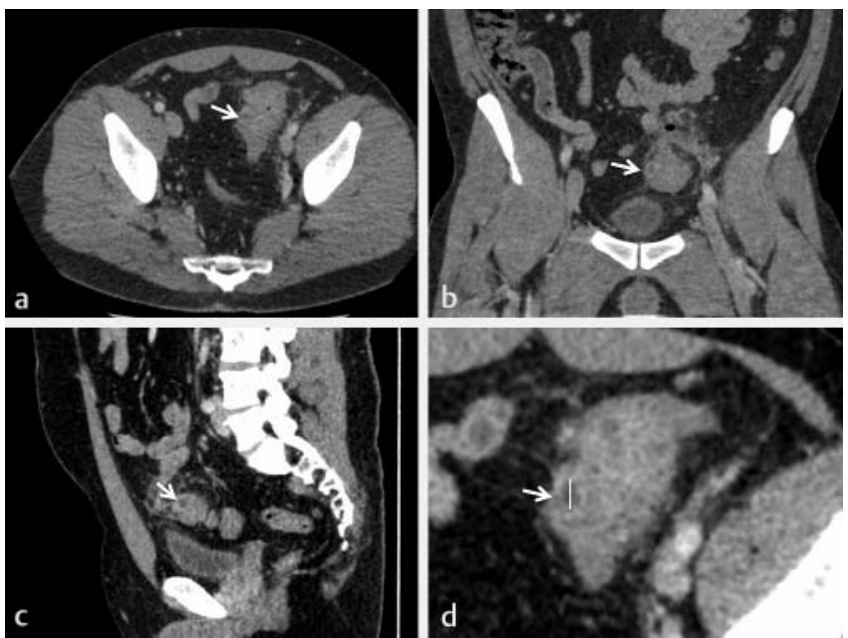

- Fig. 4 CCD type 2a: Abdominal CT scan of a 37-year-old man with intravenous contrast agent. Axial a, coronal $\mathbf{b}$, sagittal $\mathbf{c}$ and enlarged axial plane $\mathbf{d}$. In addition to the criteria of type $1 \mathrm{~b}$, this CT shows an abscess with peripheral contrast medium enhancement. Measuring $8 \mathrm{~mm}$, it corresponds to CDD type 2 a (diameter $<1 \mathrm{~cm}$ ).

tion system is an undifferentiated category for all chronic courses of the disease.

CDD type 3a, i. e., Symptomatic Uncomplicated Diverticular Disease (SUDD), presents on CT as CDD type 0 and does not have its own morphological characteristics. However, in contrast to CDD type 0 , SUDD is characterized by the persistence of clinical symptoms even though there are no longer indications of inflammation on imaging and macroscopically. This patient group and the underlying pathomechanism have not yet been characterized in detail. Strate et al. describe neuropeptidergic mucosal changes, slightly elevated calprotectin values, and histological indications of chronic persistent inflammation of the intestinal wall [41]. 


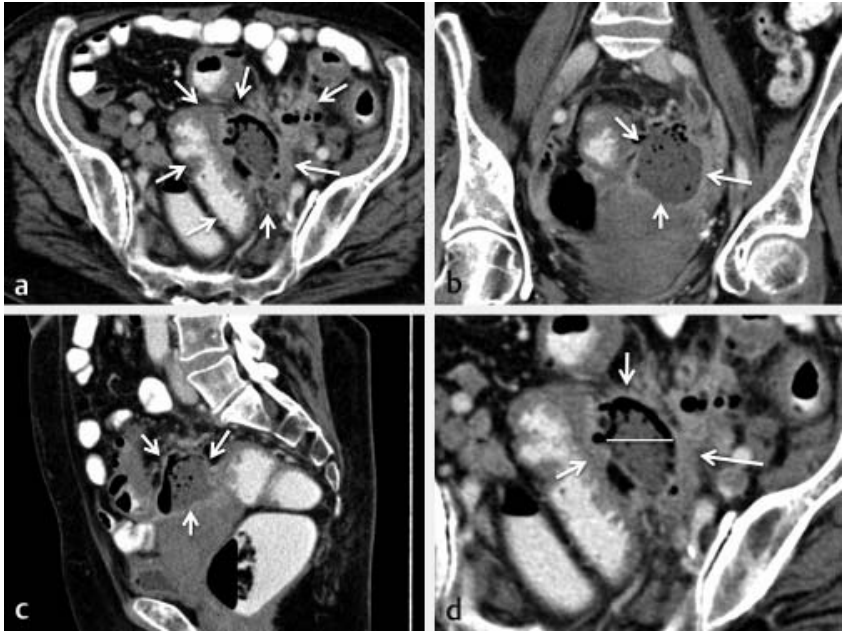

- Fig. 5 CDD type 2b: Abdominal CT scan of a 59-year-old woman with intravenous, oral, and rectal positive contrast agents. Axial a, coronal $\mathbf{b}$, sagittal $\mathbf{c}$ and enlarged axial plane $\mathbf{d}$. The criteria of CDD type $1 \mathrm{~b}$ are met, but the abscess measures $50 \mathrm{~mm}$, so it corresponds to CDD type $2 \mathrm{~b}$ (diameter $>1 \mathrm{~cm}$ ).
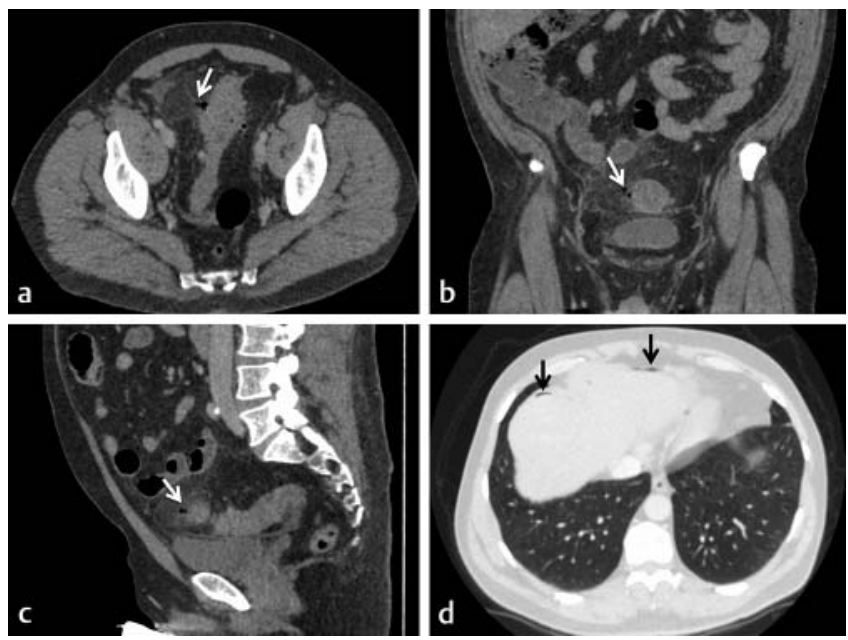

- Fig. 6 CDD type 2c: Abdominal CT scan of a 51-year-old man. Axial a, coronal $\mathbf{b}$, sagittal $\mathbf{c}$ and enlarged axial plane $\mathbf{d}$. It shows diverticulitis with free perforation (white arrows: diverticulitis with reasonable spot of perforation) and detection of free air (black arrows). This corresponds to CDD type 2c. There are no findings of generalized peritonitis.

Off-label treatment with mesalazine can be attempted [42]. However, changes in treatment recommendations can be expected in coming years.

CDD type 3b, i. e., recurrent uncomplicated diverticulitis, corresponds morphologically to non-perforated CDD type 1a or $1 \mathrm{~b}$ and can only be correctly detected and described on CT with clinical case knowledge.

With stenosis, conglomerate, or fistula formation ( $\vee$ Fig. 7 for example of stenosis), the complicated courses of CDD type $3 c$ have distinct morphological characteristics. Onur et al. provided a current description of these complications [43].


- Fig. 7 CDD type 3c: Abdominal CT scan of a 63-year-old man with intravenous contrast agent. Axial $\mathbf{a}$, coronal $\mathbf{b}$ and sagittal plane $\mathbf{c}$ and additional curved planar reformation $\mathbf{d}$. Postinflammatory stenosis with clear distension of the preceding intestinal loops, visible especially in the coronal plane. Along with fistula and conglomeration, these findings correspond to CDD type $3 \mathrm{c}$.
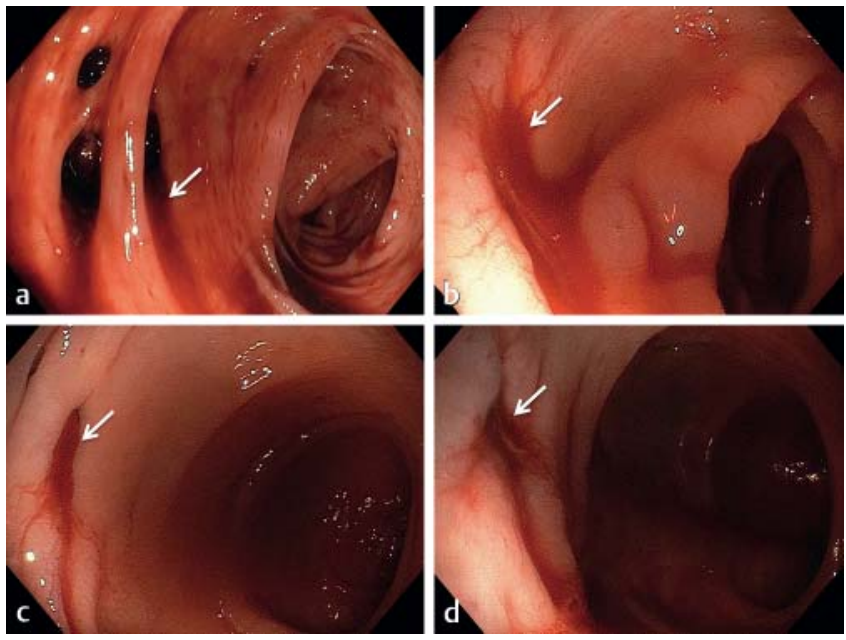

- Fig. 8 CDD type 4: Endoscopic images of different patients with bleeding into the intestinal lumen (see arrows).

\section{Diverticular bleeding}

$\mathrm{CT}$ is not primarily used to diagnose diverticular bleeding (CDD type 4). It is diagnosed by detecting a diverticulum as the source of bleeding typically on the basis of endoscopic images ( $\triangleright$ Fig. 8). It is not included in the systems prior to the CDD. It is usually primarily treated today by endoscopic hemostasis. In the case of continued bleeding, angiographic embolization or surgery is performed.

\section{Summary}

The CDD is an updated system for categorizing the stages of diverticular disease that is included in the current $\$ 2 \mathrm{k}$ guidelines 
for treating this disease. Its categories, i. e., the CDD types, combine the descriptive morphological qualities of the earlier systems as well as facilitate stratified indication determination for hospitalization and treatment in accordance with the guidelines. As a widespread disease with an increasingly younger age at onset in this country, diverticular disease is a constant in routine $C T$ diagnosis with growing significance. CDD in connection with the current guidelines allows targeted communication and decision-making for treatment.

\section{Conflict of Interest}

The authors declare that they have no conflict of interest.

\section{References}

[1] Weizman AV, Nguyen GC. Diverticular disease: epidemiology and management. Can J Gastroenterol 2011; 25: 385-389

[2] Hinchey EJ, Schaal PG, Richards GK. Treatment of perforated diverticular disease of the colon. Adv Surg 1978; 12: 85-109

[3] Wasvary H, Turfah F, Kadro O et al. Same hospitalization resection for acute diverticulitis/Discussion. The American surgeon 1999; 65: 632

[4] Hansen O, Stock W. Prophylaktische Operation bei der Divertikelkrankheit des Kolons-Stufenkonzept durch exakte Stadieneinteilung. Langenbecks Arch Chir 1999: 1257-1260

[5] Leifeld L, Germer C, Böhm S et al. S2k-Leitlinie Divertikelkrankheit/ Divertikulitis. Zeitschrift für Gastroenterologie 2014; 52: 663-710

[6] Schreyer AG, Layer G, German Society of D et al. S2k Guidlines for Diverticular Disease and Diverticulitis: Diagnosis, Classification, and Therapy for the Radiologist. Fortschr Röntgenstr 2015; 187: 676-684

[7] Böhm SK. Diagnostik und Klassifikation der Divertikelkrankheit. Visceral Medicine 2012; 28: 171-181

[8] Becker V. Pathologic-anatomic aspects of the formation and complications of diverticula. Langenbecks Arch Chir 1976; 342: 401-409

[9] Becker V. Diverticulosis. Anatomical aspects. Radiologe 1983; 23: 533 539

[10] Granlund J, Svensson T, Olen O et al. The genetic influence on diverticular disease - a twin study. Aliment Pharmacol Ther 2012; 35: 1103 1107

[11] Aldoori WH, Giovannucci EL, Rimm EB et al. A prospective study of diet and the risk of symptomatic diverticular disease in men. Am J Clin Nutr 1994; 60: 757-764

[12] Böhm S. Epidemiologie, natürlicher Verlauf, Prognose. In: Kruis WLL, Hrsg. Divertikelkrankheit. Bremen: Uni-Med; 2010

[13] Carlson AJ, Hoelzel F. Relation of diet to diverticulosis of the colon in rats. Gastroenterology 1949; 12: 108-115

[14] Commane DM, Arasaradnam RP, Mills S et al. Diet, ageing and genetic factors in the pathogenesis of diverticular disease. World J Gastroenterol 2009; $15: 2479-2488$

[15] Etzioni DA, Mack TM, Beart RW Jr. et al. Diverticulitis in the United States: 1998-2005: changing patterns of disease and treatment. Ann Surg 2009; 249: 210-217

[16] Fisher N, Berry CS, Fearn T et al. Cereal dietary fiber consumption and diverticular disease: a lifespan study in rats. Am J Clin Nutr 1985; 42: $788-804$

[17] Masoomi H, Buchberg BS, Magno C et al. Trends in diverticulitis management in the United States from 2002 to 2007. Arch Surg 2011; 146: $400-406$
[18] Painter NS, Burkitt DP. Diverticular disease of the colon: a deficiency disease of Western civilization. Br Med J 1971; 2: 450-454

[19] Petruzziello L, lacopini F, Bulajic M et al. Review article: uncomplicated diverticular disease of the colon. Aliment Pharmacol Ther 2006; 23 : $1379-1391$

[20] Strate LL. Lifestyle factors and the course of diverticular disease. Dig Dis 2012; 30: 35-45

[21] Aldoori WH, Giovannucci EL, Rimm EB et al. Use of acetaminophen and nonsteroidal anti-inflammatory drugs - A prospective study and the risk of symptomatic diverticular disease in men. Archives of Family Medicine 1998; 7: 255-260

[22] Hjern F, Wolk A, Hakansson N. Obesity, physical inactivity, and colonic diverticular disease requiring hospitalization in women: a prospective cohort study. Am J Gastroenterol 2012; 107: 296-302

[23] Kopylov U, Ben-Horin S, Lahat A et al. Obesity, metabolic syndrome and the risk of development of colonic diverticulosis. Digestion 2012; 86: 201-205

[24] Rosemar A, Angeras U, Rosengren A. Body mass index and diverticular disease: a 28-year follow-up study in men. Dis Colon Rectum 2008; 51 : $450-455$

[25] Sakuta H, Suzuki T. Prevalence rates of type 2 diabetes and hypertension are elevated among middle-aged Japanese men with colonic diverticulum. Environmental health and preventive medicine 2007; 12: 97-100

[26] Strate LL, Liu YL, Aldoori WH et al. Physical activity decreases diverticular complications. Am J Gastroenterol 2009; 104: 1221 - 1230

[27] Lembcke B. Diagnosis, differential diagnoses, and classification of diverticular disease. Visceral Medicine 2015; 31: 95-102

[28] Klarenbeek BR, de Korte N, van der Peet DL et al. Review of current classifications for diverticular disease and a translation into clinical practice. International Journal of Colorectal Disease 2012; 27: 207 - 214

[29] Tack D, Bohy P, Perlot I et al. Suspected Acute Colon Diverticulitis: Imaging with Low-Dose Unenhanced Multi-Detector Row CT 1. Radiology 2005; 237: 189-196

[30] Werner A, Diehl S, Farag-Soliman M et al. Multi-slice spiral CT in routine diagnosis of suspected acute left-sided colonic diverticulitis: a prospective study of 120 patients. European radiology 2003; 13: 2596-2603

[31] Sessa B, Galluzzo M, lanniello $S$ et al. Acute perforated diverticulitis: assessment with multidetector computed tomography. Seminars in UItrasound, CT and MRI: Elsevier 2016: 37-48

[32] Öistämö E, Hjern F, Blomqvist L et al. Cancer and diverticulitis of the sigmoid colon. Differentiation with computed tomography versus magnetic resonance imaging: preliminary experiences. Acta radiologica 2013; 54: $237-241$

[33] Thorisson A, Smedh K, Torkzad M et al. CT imaging for prediction of complications and recurrence in acute uncomplicated diverticulitis. International journal of colorectal disease 2016; 31: 451-457

[34] Ambrosetti P. Acute left-sided colonic diverticulitis: clinical expressions, therapeutic insights, and role of computed tomography. Clinical and experimental gastroenterology 2016; 9: 249

[35] Andeweg CS, Wegdam JA, Groenewoud J et al. Toward an evidencebased step-up approach in diagnosing diverticulitis. Scandinavian journal of gastroenterology 2014; 49: 775-784

[36] Karidis NP, Dimitroulis D, Kouraklis G. The role of abdominal imaging in cases with a high probability of acute left-sided colonic diverticulitis based on a clinical scoring system. Annals of surgery 2013; 258: e14

[37] Rao P, Rhea J, Novelline R et al. Helical CT with only colonic contrast material for diagnosing diverticulitis: prospective evaluation of $150 \mathrm{pa}-$ tients. Am J Roentgenol American journal of roentgenology 1998; 170 : $1445-1449$ 
[38] Kircher MF, Rhea JT, Kihiczak D et al. Frequency, sensitivity, and specificity of individual signs of diverticulitis on thin-section helical CT with colonic contrast material: experience with 312 cases. American Journal of Roentgenology 2002; 178: 1313-1318

[39] Buckley O, Geoghegan T, O'Riordain D et al. Computed tomography in the imaging of colonic diverticulitis. Clinical radiology 2004; 59 : $977-$ 983

[40] Lohrmann C, Ghanem N, Pache G et al. CT in acute perforated sigmoid diverticulitis. European journal of radiology 2005; 56: 78-83
[41] Strate LL, Modi R, Cohen E et al. Diverticular Disease as a Chronic Illness: Evolving Epidemiologic and Clinical Insights. American Journal of Gastroenterology 2012; 107: 1486-1493

[42] Kruis W, Meier E, Schumacher M et al. Randomised clinical trial: mesalazine (Salofalk granules) for uncomplicated diverticular disease of the colon-a placebo-controlled study. Alimentary pharmacology \& therapeutics 2013; 37: 680-690

[43] Onur MR, Akpinar E, Karaosmanoglu AD et al. Diverticulitis: a comprehensive review with usual and unusual complications. Insights into Imaging 2017; 8: 19-27 